\title{
Ascending Cholangitis secondary to migrated embolization coil of gastroduodenal artery pseudo-aneurysm a case report
}

\author{
Haithem Zaafouri ${ }^{1 *}$, Anis Hasnaoui ${ }^{1}$, Sonia Essghaeir ${ }^{2}$, Dhafer Haddad ${ }^{1}$, Meriam Sabbah $^{3}$, Ahmed Bouhafa ${ }^{1}$
} Jamel Kharrat ${ }^{3}$ and Anis Ben Maamer ${ }^{1}$

\begin{abstract}
Background: Gastroduodenalartery (GDA) pseudo-aneurysms are very rare. Their clinical importance lies in the eventuality of rupture, causing bleeding and ultimately exsanguination.

Case presentation: We report the case of a man, with prior history of biliary surgery, presenting with haemobilia secondary to a rupture of GDA pseudo-aneurysm eroding the main bile duct. The patient was treated with coil embolization. This technique is considered to be safe. However, on the long term, some complications may occur. In our case, the patient presented with cholangitis subsequent to coil migration in the lower bile duct. This situation was managed using endoscopic retrograde cholangiopancreatography (ERCP) allowing coil extraction with favorable evolution.

Conclusions: GDA pseudo-aneurysms are very rare. Bleeding, secondary to the rupture of these lesions, is a serious complication that could lead to death. Diagnosis and treatment of ruptured GDA pseudo-aneurysms rely on angiography. This method is considered to be safe. Cholangitis secondary to coil migration in the main bile duct is exceedingly rare,but remains an eventuality that physicians should be cognizant of.
\end{abstract}

Keywords: Gastroduodenal artery, Pseudo-aneurysm, Haemobilia, Embolization coil, Cholangitis

\section{Background}

Splanchnic artery aneurysms are rare entities. They are mainly cited in literature as case reports rendering their prevalence hard to determine [1]. Aneurysms of the gastroduodenal artery (GDA) are the least common [2]. Their clinical importance resides in the fact that they can be rapidly fatal if ruptured. The management of these conditions relies on endovascular embolization. This technique is considered to be safe. However, on the long term, seldom complications may occur. We report a case of upper gastrointestinal bleeding secondary to a ruptured pseudo-aneurysm of the gastroduodenal artery after choledochotomy, treated with endovascular

\footnotetext{
* Correspondence: zaafouri.haithem@hotmail.fr

${ }^{1}$ Department of General Surgery Habib Thameur Hospital, Ali Ben Ayed

Street's 2037 Montfleury, Tunis, Tunisia

Full list of author information is available at the end of the article
}

embolization, and subsequent migration of a coil in the main bile duct, causing severe cholangitis.

\section{Case presentation}

A 55-year-old man, with previous history of alcohol consumption, presented to our institution with a 6-day history of right upper quadrant pain, fever and progressive jaundice. Physical examination showed a temperature of $38{ }^{\circ} \mathrm{C}$, a pulse rate of $98 / \mathrm{min}$, a blood pressure of $10 /$ $7 \mathrm{~cm} \mathrm{Hg}$, scleral icterus and right upper quadrant pain with no rebound. Laboratory blood tests showed a leukocyte count of $12,300 / \mathrm{ml}$, C-reactive protein of $215 \mathrm{mg} / \mathrm{l}$, a conserved renal function. His liver function tests revealed a total bilirubin of $130 \mathrm{umol} / \mathrm{l}$, an alanine transaminase (ALT) of $213 \mathrm{U} / \mathrm{l}$, a gammaglutamyltranspeptidase $(\gamma-\mathrm{GT})$ of $686 \mathrm{U} / \mathrm{l}$ and an alkaline phosphatase (ALP) of $284 \mathrm{U} / \mathrm{l}$. Amylase level and 
prothrombin time were normal. Abdominal ultrasonography foundcholelithiasis and a mild dilatation of both the extrahepatic and intrahepatic biliary tract. The obstacle was not identified. CT scan confirmed the presence of several stones impacted in the common bile duct, upstream biliary tree dilatation, and an enlarged pancreatic head with adjacent peripancreatic inflammation. We retained the diagnosis of acute pancreatitis with ascending cholangitis. The patient was admitted and antibiotics were then intravenously administered. Twenty-four hours later, he had an endoscopic retrograde cholangiopancreatography (ERCP) with sphincterotomy and stones extraction with favorable evolution (Fig. 1). The patient was discharged 3 days later.

A laparoscopic cholecystectomy was scheduled, after regression of peripancreatic inflammation, 3 months later. Due to dissection difficulties, we converted to a Kocher's incision to complete the cholecystectomy. Transcystic cholangiography showed residual stones. We performed choledocotomy with two stones retrieval and T-tube choledochostomy. Immediate post-operative course was uneventful and T-tube cholangiography was normal. The patient was discharged in the $5^{\text {th }}$ post-operative day.

Two weeks later, the patient presented with hematemesis and melena. On examination, he had icterus, blood pressure of $12 / 8 \mathrm{~cm} \mathrm{Hg}$ and a pulse of 85 beats per

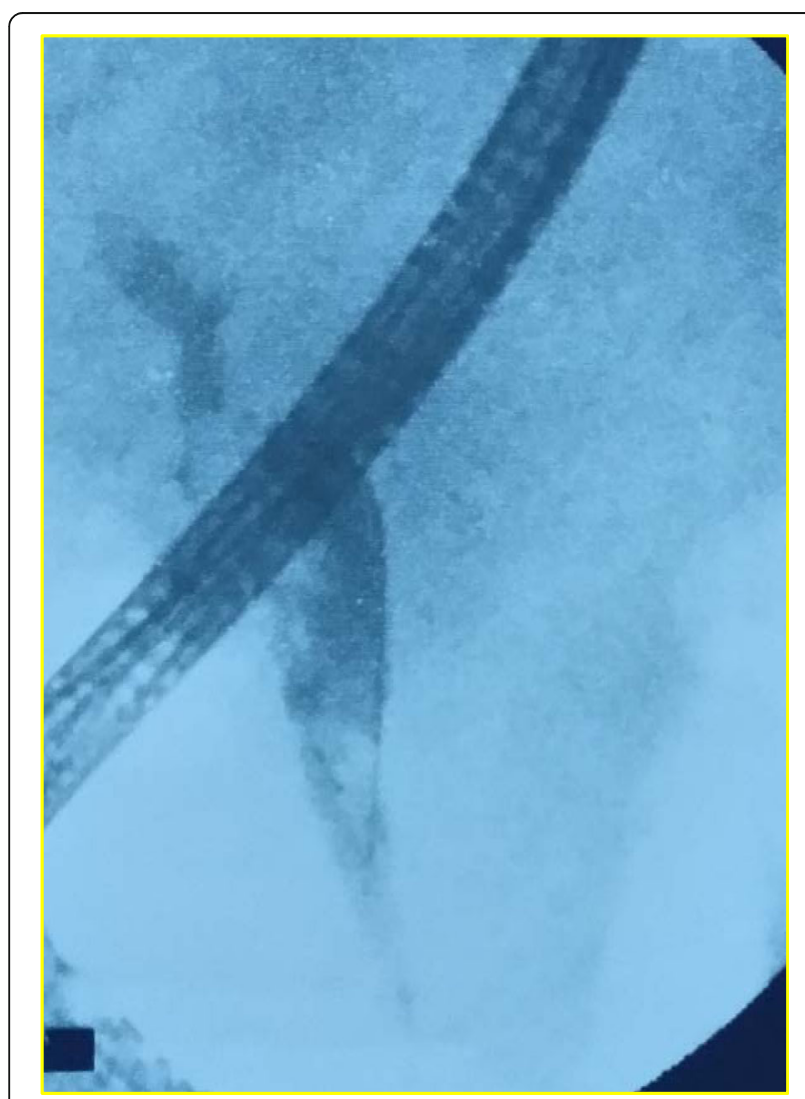

Fig. 1 ERCP showing stones in the main bile duct minute. On digital rectal examination, he had melena. There was no blood exteriorization from the T-tube. Blood tests showed a hemoglobin level at $96 \mathrm{~g} / \mathrm{l}$, a total bilirubin of $46 \mathrm{umol} / \mathrm{l}$, an ALT of $225 \mathrm{U} / \mathrm{l}$, a $\gamma$-GT of 516 $\mathrm{U} / \mathrm{l}$. He underwent upper gastrointestinal endoscopy showing mycotic esophagitis and erosive bulbitis with no active bleeding. Lateral duodenoscopy revealed no bleeding from the papilla. CT scan showed infiltration of subhepatic fat and magnetic resonance cholangiopancreatography was normal. During hospitalization, the patient was hemodynamically stable, without further drop in hemoglobin level. He was discharged with an appointment to our outpatient department.

After 1 month of being discharged, the patient presented with recurrence of upper gastrointestinal bleeding and haemobilia with blood exteriorization from the T-tube. On examination, he was hemodynamically stable, he had scleral icterus and right upper quadrant pain. On digital rectal examination, he had melena. Hemoglobin level was at $85 \mathrm{~g} /$ $\mathrm{l}$ and his liver function tests revealed icteric cholestasis. A CT-angiography was performed showing a pseudoaneurysm of the gastroduodenal arterywith probable erosion of the main bile duct (Fig. 2).

In the third day post admission,a massivebleeding and hemorrhagic shock occurred. Hemoglobin level was at $40 \mathrm{~g} /$ l. The patient was admitted to the intensive care department. After resuscitation and transfusion his condition was relatively stabilized, and he was addressed for urgent embolization. Coeliac arteriography confirmed the bleeding from the pseudo-aneurysm of the gastroduodenal artery. Embolization using three coils achieved successful hemostasis with preserved permeability of the gastroduodenal artery. The immediate post-embolization period passed without any complications. The patient was discharged 6 days later after T-tube removal. Then he was lost to follow-up.

Twenty months later, the patient presented with Charcot's triad. Physical examination showed a temperature of $40{ }^{\circ} \mathrm{C}$, heart rate of $120 / \mathrm{min}$, blood pressure of $14 / 9$ $\mathrm{cmHg}$, icterus and right upper quadrant tenderness. On blood tests, leukocyte count was $22,770 / \mathrm{ml}$, C-reactive protein level $260 \mathrm{mg} / \mathrm{l}$, and conserved renal function. His liver function tests revealed a total bilirubin of 355 umol/l, conjugated bilirubin of $195 \mathrm{umol} / \mathrm{l}$, an ALT of $215 \mathrm{U} / \mathrm{l}$, a $\gamma$-GT of $729 \mathrm{U} / \mathrm{l}$ and an alkaline phosphatase of $126 \mathrm{U} / \mathrm{l}$. Prothrombin time was 50\%. On ultrasonography, we noted dilatation of both the extrahepatic and intrahepatic biliary tract. CT scan revealed a hyper-dense obstacle of the lower bile duct (Fig. 3).

ERCP showed the presence, in the lower bile duct, of an intraluminal coil and stones, with upstream biliary tree dilatation (Fig. 4). An extraction of the coil and fragmented stones was carried out and vacuity of bile ducts was attained. Following this, the patient recovered uneventfully and was discharged 8 days later. 


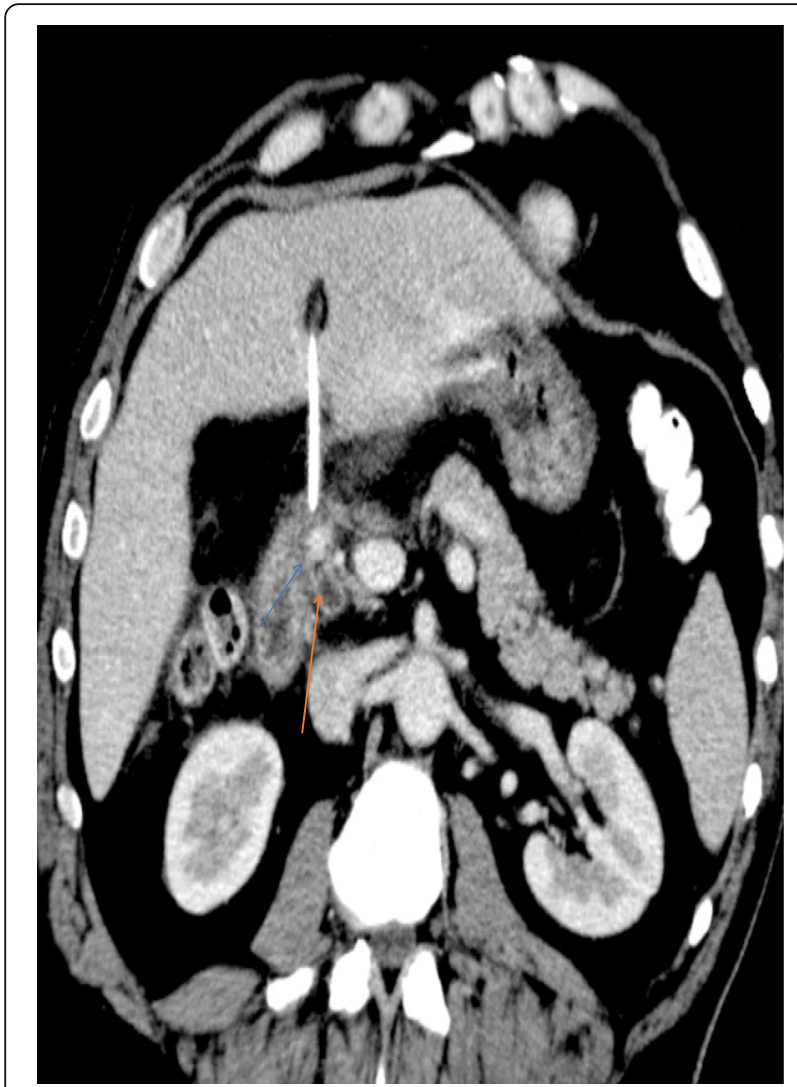

Fig. 2 CT-angiography showing a pseudo-aneurysm of the gastroduodenal artery with probable erosion of the main bile duct

\section{Discussion}

\section{Etiology of GDA pseudo-aneurysms}

Aneurysms of GDA are very rare. They are estimated to be less than $1.5 \%$ of all splanchnic artery aneurysms [2]. They are divided into two types: True aneurysms and pseudo-aneurysms like our case. GDA pseudoaneurysms are generally secondary to acute or chronic pancreatitis, cholangitis, traumatic or iatrogenic causes [3-6]. All these factors were present in our case. It is most likely that the iatrogenic factor in an inflammatory environment precipitated the formation of the pseudoaneurysm. This is the second case of GDA pseudoaneurysm after choledochotomy in the English literature. The first case was reported byEkeland and al in 1974 [7].

\section{Symptomatology}

GDA pseudo-aneurysms could remain silent for a long time and be revealed accidentally in an imaging study. On the contrary, theycould be symptomatic. Revelation modes are mainly compression, and bleeding. Bleeding is considered to be the most serious complication, as it can rapidly lead to a hemorrhagic shock, and ultimately death. It can occur after the rupture of the pseudoaneurysm in the peritoneum, the retroperitoneum or in

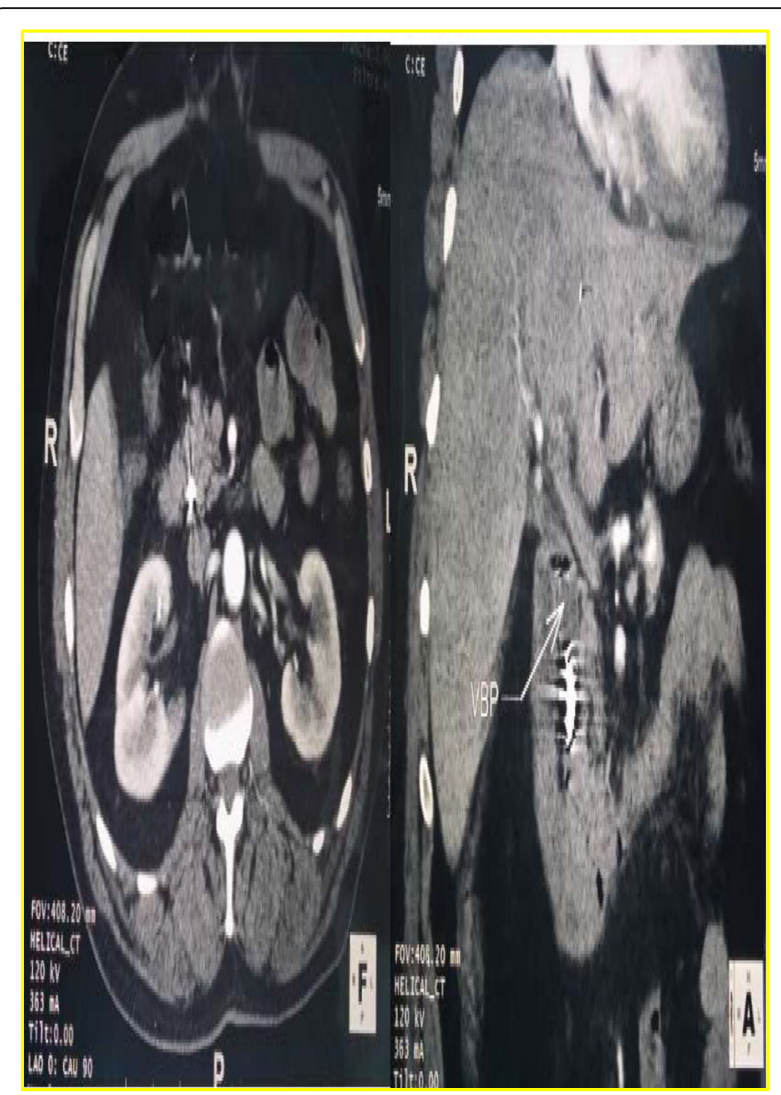

Fig. 3 Axial (Left picture) and Frontal (right picture) CT-scan images, showing a hyper-dense obstacle in the bile duct

the gastrointestinal tract by way of the duodenum or the bile duct causing haemobilia like in our case [8].

Rupture of a GDA pseudo-aneurysm in the main bile duct is exceedingly rare. Only few cases in the literature have been reported [4]. Symptoms of haemobilia are, classically, abdominal pain, upper gastrointestinal hemorrhage and jaundice. The complete triad known as Quincke's triad occurred only in $22 \%$ of 222 cases of haemobilia, in the review of Green and al. [9]. Our patient presented this triad, which adds to the particularities of this case.

\section{Diagnosis and treatment}

In our case, the patient presented to our institution, 2 weeks after biliary surgery, with upper gastrointestinal bleeding. Usedexplorations to detect an etiology for this bleeding, including upper gastrointestinal endoscopy and lateral duodenoscopy, were inconclusive. This is may be due to the fact that the patient stopped bleeding as would suggest the hemodynamic and hemoglobin level stabilities. Therefore, the intermittence of a bleeding could be a source of false negatives if sensitive diagnostic tools are not used. In the recent literature, only $12 \%$ of haemobilia cases were diagnosed endoscopically [10]. 


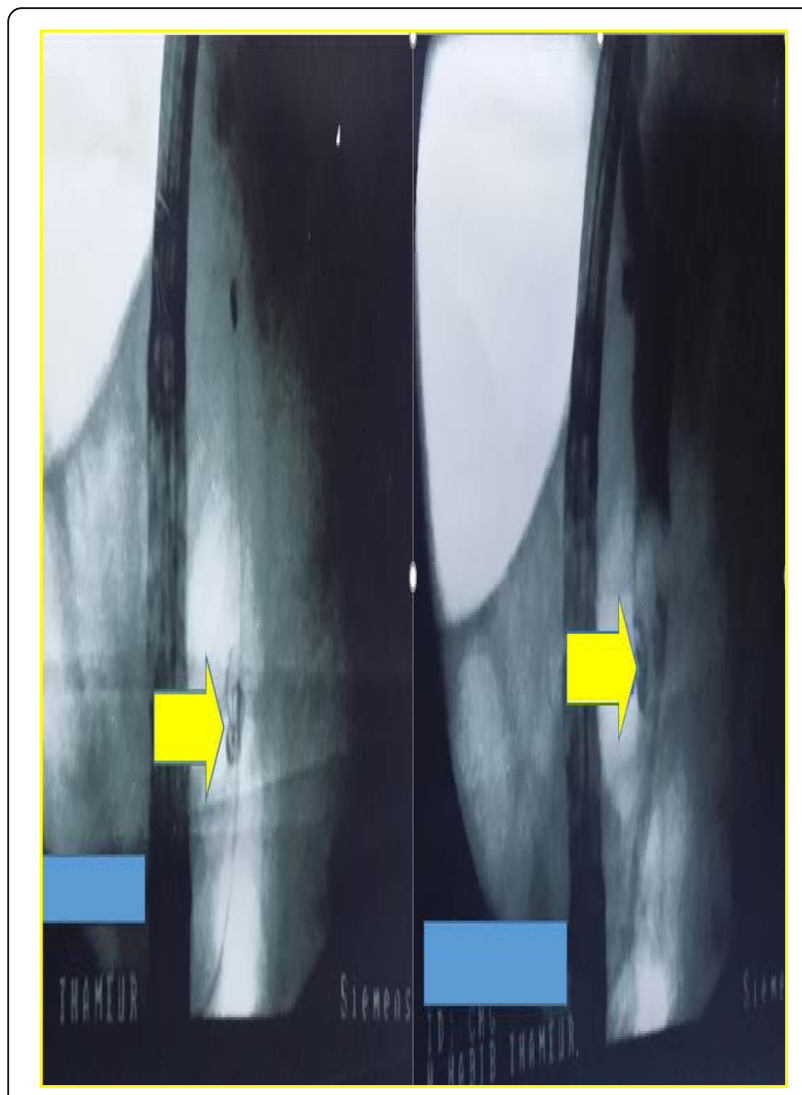

Fig. 4 ERCP, before (Left picture) and after (Right picture) contrast agent injection, showing the coil (Yellow arrow) in the lower main bile duct

Arteriography is the most valuable diagnostic test to detect Splanchnic artery aneurysms and the exact location of bleeding $[11,12]$. However, this technique requires a trained interventional radiologist. CT angiography and magnetic resonance angiography could be also used in the diagnostic arsenal, when arteriography is not available, with high threshold of detection of Splanchnic artery aneurysms [13].

Management of GDA pseudo-aneurysms relies either on surgery or angiographic embolization. The latter, if available, is considered the safer and more effective option, especially in the active bleeding patient $[13,14]$. Success rate is estimated to be around 80 to $100 \%$ [9]. A variety of embolic agents have been used. In our case, we used three metallic coils with preserved permeability of the gastroduodenal artery. Nevertheless,surgery remains the only option for proximal GDA pseudo-aneurysms [4] and should be considered if angiographic embolization fails or is unavailable or contraindicated $[15,16]$.

\section{Rare complication after GDA embolization}

After embolization of Splanchnic artery aneurysms, some complications could occur. In the short term, accidentalembolization of the wrong vessel with ensuing infarction is may be the most serious complication. In the long term, complications are rare. In our case, 20 months after embolization, the patient presentedwith cholangitis secondary to coil migration from the embolized GDA pseudo-aneurysm. To our knowledge, this is the first case to be published in the English literature. Some cases of cholangitis after coil embolization of hepatic arteries were reported [17-19]. The best management of these conditions is through ERCP, especially in severe cholangitis like in our case. AS for surgery, it could be indicated after ERCP failure.

\section{Conclusion}

GDA pseudo-aneurysms are very rare. Bleeding, secondary to the rupture of these lesions, is a serious complication that could lead to death. Thus, surgeons must keep a high index of suspicion, in the set of patients with history of biliary surgery, presenting with upper gastrointestinal bleeding. Diagnosis and treatment of ruptured GDA pseudo-aneurysms, rely on angiography. This method is considered to be safe. Cholangitis secondary to coil migration in the main bile duct is exceedingly rare,but remains an eventuality that physicians should be cognizant of.

\section{Abbreviations}

ALP: Alkaline phosphatase; ALT: Alanine transaminase; ERCP: Endoscopic retrograde cholangiopancreatography; GDA: Gastroduodenal artery; $\gamma^{-}$ GT: Gamma-glutamyltranspeptidase

\section{Acknowledgements}

All the authors contributed to this work. The idea of the publication of this paper came after discussion between Haithem ZAAFOURI and Sonia ESSGAHEIR.

Anis HASNAOUI, Meriam SABBAH and Dhafer HADDAD participated in acquisition and interpretation of data.

Haithem ZAAFOURI and Anis HASNAOUI participated in the writing of paper. Finally, all Professors Ahmed BOUHAFA, Jamel KHARRAT and Anis BEN MAAMER approved the final version of manuscript.

\section{Funding}

We have no conflict of interest to declare.

\section{Availability of data and materials}

Data and materials are available at the request of the readers.

\section{Authors' contributions}

Conception and design of study: HZ, SE. Acquisition of data: AH, DH. Data analysis and interpretation: MS. Drafting of manuscript: $\mathrm{HZ}$ and $\mathrm{AH}$. Approval of final version of manuscript: $A B, J K$ and $A B M$.

Competing interests

The authors declare that they have no competing interests.

Consent for publication

The patient has given us a written permission to use his medical data in this manuscript.

Ethics approval and consent to participate Not applicable. 


\section{Publisher's Note}

Springer Nature remains neutral with regard to jurisdictional claims in published maps and institutional affiliations.

\section{Author details}

${ }^{1}$ Department of General Surgery Habib Thameur Hospital, Ali Ben Ayed Street's 2037 Montfleury, Tunis, Tunisia. ${ }^{2}$ Department of Radiology Habib Thameur Hospital, Tunis, Tunisia. ${ }^{3}$ Department of Gastroenterology Habib Thameur Hospital, Tunis, Tunisia.

Received: 24 December 2016 Accepted: 16 March 2017

Published online: 23 March 2017

\section{References}

1. Saltzberg SS, Maldonado TS, Lamparello PJ, et al. Is endovascular therapy the preferred treatment for all visceral artery aneurysms? Ann Vasc Surg. 2005;19(4):507-15.

2. Messina LM, Shanley CJ. Visceral artery aneurysms. Surg Clin North Am. 1997:77(2):425-42.

3. Welling TH, Williams DM, Stanley JC. Excessive oral amphetamine use as a possible cause of renal and splanchnic arterial aneurysms: a report of two cases. J Vasc Surg. 1998;28(4):727-31.

4. Fodor M, Fodor L, Ciuce C. Gastroduodenal artery pseudoaneurysm ruptured in the common bile duct. Acta Chir Belg. 2010;110(1):103-5.

5. Lo Bue S, Denoel A. Gastroduodenal artery pseudoaneurysm after cholecystectomy. Acta Chir Belg. 2003:103(4):416-41.

6. Mawaddah A, Abrar N, Reda J, Yousef Q, Murad A. Delayed hemobilia due to hepatic artery pseudo-aneurysm: a pitfall of laparoscopic cholecystectomy. BMC Surg. 2016;16:59.

7. Ekeland A, Ofstad E, Stiris G. Hemobiliapseudoaneurysm in the gastroduodenal artery following choledochotomia. A Case report. Acta Chir Scand. 1974;140(5):422-7.

8. Sessa C, Tinelli G, Porcu P, et al. Treatment of visceral artery aneurysms: a description of a retrospective series of 42 aneurysms in 34 patients. Ann Vasc Surg. 2004;18:695-703.

9. Green MH, Duell RM, Johnson CD, Jamieson NV. Haemobilia. Br J Surg. 2001; 88:773-86.

10. Napolitano $V$, et al. A severe case of hemobilia and biliary fistula following an open urgent cholecystectomy. World J Emerg Surg. 2009:4:37.

11. Mandel R, Jaques P, Sanofsky S, Matthew A. Non-operative management of peripancreatic arterial aneurysms. Ann Surg. 1987;205:126-8.

12. Bohl JL, Dossett LA, Grau AM. Gastroduodenal artery pseudoaneurysm associated with haemosuccuspancreaticus and obstructive jaundice. J Gastrointest Surg. 2007:11:1752-4.

13. Horton KM, Smith C, Fishman EK. MDCT and 3D CT angiography of splanchnic artery aneurysms. AJR Am J Roentgenol. 2007;189(3):641-7.

14. Madanur MA, et al. Pseudoaneurysm following laparoscopic cholecystectomy. Hepatobiliary Pancreat Dis Int. 2007;6(3):294-8.

15. Tsu-Te L, Ming-Chih H, Han-Chieh L, Full-Young C, Shou-Dong L. Lifethreatening hemobilia caused by hepatic artery pseudoaneurysm: a rare complication of chronic cholangitis. World J Gastroenterol. 2003;9(12):2883-4.

16. Cattan $P$, et al. Hemobilia caused by a pseudoaneurysm of the hepaticartery diagnosed by EUS. Gastrointest Endosc. 1999;49(2):252-5.

17. Turaga KK, Amirlak B, Davis RE, Yousef K, Richards A, Fitzgibbons RJ. Cholangitis after coil embolization of an iatrogenic hepatic artery pseudoaneurysm: an unusual case report. Surg Laparosc Endosc Percutan Tech. 2006;16(1):36-8.

18. Zervos X, Molina E, Larsen MF. Cholangitis secondary to migrated metallic coils in the common bile duct. Acta Gastroenterol Latinoam. 2013:43(2):146-8.

19. Soondoos R, Manju DC, Khaled A, Glen S, Neil DM. Vascular coil erosion into hepaticojejunostomy following hepatic arterial embolisation. BMC Surg. 2015:15:51.

\section{Submit your next manuscript to BioMed Central and we will help you at every step:}

- We accept pre-submission inquiries

- Our selector tool helps you to find the most relevant journal

- We provide round the clock customer support

- Convenient online submission

- Thorough peer review

- Inclusion in PubMed and all major indexing services

- Maximum visibility for your research

Submit your manuscript at www.biomedcentral.com/submit 